\title{
From Servant to Queen: A Journey through Victorian Mathematics
}

\section{Reviewed by Sloan Evans Despeaux}

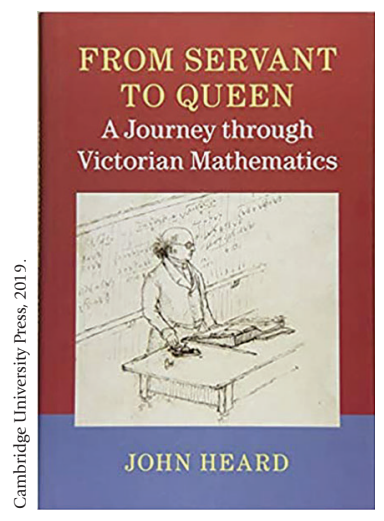

$\overline{\text { From Servant to Queen: A Journey }}$ through Victorian Mathematics

by John Heard

What is pure mathematics good for? Today's mathematicians are faced with this question on a daily basis, especially when applying for grants or appealing to university administrations. Our STEM-focused world holds many parallels with Victorian Britain, associated by many today with usefulness, technical innovation, and practicality. Where did pure mathematics fit in that time and place, and how was it viewed by the public? In fact, the practice of pure mathematics and its public reputation underwent significant change in Britain during Victoria's more than six-decade reign. John Heard's From Servant to Queen: A Journey through Victorian Mathematics seeks to track this change. In this concise volume of 267 pages, Heard "stresses pure mathematicians in society, rather than the content of pure mathematics itself... The actual content of mathematics is not absent from this story, but it does take a back seat" [p. 8]. The central question of the book is how pure mathematics, a discipline commonly regarded as having no immediate practical uses, emerged as a respected field of study in Britain during an era when utility was so highly prized.

Sloan Evans Despeaux is a professor of mathematics at Western Carolina University. Her email address is despeaux@wcu. edu.

Communicated by Notices Book Review Editor Stephan Ramon Garcia.

For permission to reprint this article, please contact: reprint-permission aams.org.

DOI: https://dx.doi.org/10.1090/noti2287
Heard begins his journey through Victorian mathematics by giving a wide overview of mathematics in Britain in a succinct but unrushed way, starting from John Dee's mathematical preface to Euclid's Elements of 1570 to the 1850s. Central to this overview is the role of "mixed" mathematics ("a term for which the modern 'applied mathematics' is almost, but not quite, a synonym" [p. 2]) as a servant to natural philosophy. Another important theme is the rift between British and Continental mathematics that began with the Newton/Leibniz priority controversy in the late seventeenth century. This controversy persisted as a divisive force into the beginning of the nineteenth century, with British mathematicians following different research paths using different notation, so much so that they could barely decipher the work of their Continental counterparts. These barriers began to weaken as mathematicians such as James Toplis, Robert Woodhouse, and the undergraduate members of the Analytical Society introduced Continental methods into British mathematics, especially the mathematics of Cambridge.

Heard pursues themes of mathematical isolation and self-styled heroicism in the Victorian period through four case studies. He highlights the pure mathematical careers of J. W. L. Glaisher, H. J. S. Smith, Henry Baker, and Percy MacMahon. At center stage are the frustrations these men felt while pursuing pure mathematical research in Britain. For example, H. J. S. Smith's life at Oxford was mathematically isolating, and he was buried in administrative work. Although his work in number theory was in line with what was being done on the Continent, it became clear that it had been ignored by the mathematicians there when the Académie des Sciences set as its 1882 Grand Prix question a problem that Smith had published a solution to fifteen years earlier. Glaisher experienced great success in his teaching duties as a Cambridge lecturer and in his service to many learned societies. However, he was held back in his 
analytical research by Cambridge mathematical traditions. As the sole editor of the Quarterly Journal of Pure and Applied Mathematics and the Messenger of Mathematics for decades, he provided financial support for the journals and gave young researchers the opportunity to publish mathematics, but he also struggled to fill these outlets with quality content. Baker, also at Cambridge, felt his "old school" approach to the theory of functions was losing relevancy and made a successful change in his research track to geometry. Both Glaisher and Baker recognized the importance of forming research schools and attracting students. For his part, Glaisher advocated reforms to the Cambridge Mathematical Tripos examination, and Baker hosted research "tea parties" that stoked his school of geometry. However, Heard argues that "the British clung to a vision of the mathematician as hero, engaged in a personal struggle with his symbols and equations" [p. 126]. Moreover, as compared to the new German non-constructive proof methods, "British mathematicians, many of whom regarded these new forms of 'proof' with suspicion, clung to the heroic methods of constructive proof that had been so productive for Cayley and Sylvester" [p. 127]. Such heroic acts of calculation were well fitted to Percy MacMahon's mathematical abilities, where he successfully pursued first invariant theory and later combinatorics.

Continuing with his theme of mathematical isolation, Heard characterizes Victorian Britain generally as an "international backwater" [p. 145]. It would be helpful to put the situation in Victorian Britain into context by contrasting it against something more fine-grained than the concept of the "Continent." Moreover, an examination of connections with the US and the British Empire would have painted a more complete picture. Broad-brush statements such as "few British authors published pure mathematics in foreign-language journals, with an average annual total output of less than 25 pages" [p. 139] miss out on intermittent but significant efforts by British pure mathematicians to publish abroad [2, p. 85]. Heard is right to say that the number of British pure mathematicians who participated in print internationally was limited, but averages miss a core group of pure mathematicians who did actively participate.

Through several more case studies, Heard puts Victorian applied mathematicians into a much more flattering light than their pure mathematical counterparts. James Clerk Maxwell, Lord Rayleigh, William Thomson, George Gabriel Stokes, W. K. Clifford, and George Biddell Airy are presented as men whose work in applied mathematics earned them public interest and acclaim. Unifying these applied mathematical case studies are the questions that surrounded the existence of an ether as opposed to a vacuum in the universe.

In this environment of public approbation for applied mathematics, how did pure mathematicians justify their practices? Heard first considers the role of the London Mathematical Society (LMS) in legitimizing British pure mathematics. From its humble beginnings as a student organization of University College London, the LMS soon cultivated a membership that was heavy with Cambridge wranglers (those who had scored highest on the Tripos), and "the combination of a Cambridge education and membership of the LMS came to dominate the Victorian pure mathematical scene" [p. 56]. The Society's Proceedings followed a strict refereeing policy and contained high-level content. Using data from the reviews of the Jahrbuch über die Fortschritte der Mathematik, Heard gives a general overview of pure mathematics journal publications in Britain from 1868 to 1900 and points out that besides sustaining their own journal, LMS members authored the lion's share of all British pure mathematical journal publications.

Heard argues that Cambridge mathematics came to dominate the Society and its Proceedings, and international contributions weakened during the century. "Thus the Proceedings was ineffective as a means of keeping British mathematicians abreast of developments on the Continent, and members who relied on it for this purpose would have had a very one-sided view of mathematical progress" [p. 83]. Heard equates "international" with "Continental" in this discussion. While not numerous, the number of international contributions in the Proceedings actually doubled from the 1880s to 1890s, due in large part to J. H. Michell in Australia and US contributors such as L. E. Dickson, E. H. Moore, G. A. Miller, and W. E. Story [1, p. 245]. Again, this discussion could have benefitted from recognizing and analyzing the ties between British pure mathematicians and those in the US and the British Empire.

Besides its Proceedings, Heard considers other ways the LMS defined its mission as a society. Interpreting its "Rule 1, " which gave as the Society's goals "the promotion and extension of Mathematical knowledge," [p. 81] as an imperative to avoid controversy, the LMS drew strict limits on what topics it would consider; for example, it deemed all discussion of mathematics education strictly outside of its purview. This limited role promoted peaceful meetings but limited the potential lobbying power the Society might have had for mathematics. Heard also argues that the LMS missed an opportunity at forging international ties and emerging scholars by awarding its De Morgan medal to old guard British members as opposed to younger or foreign mathematicians.

After dismissing the LMS as a legitimizing force for pure mathematicians in Victorian Britain, Heard then considers two "apologias for pure mathematicians," one made by James Joseph Sylvester in 1869 and another by H. J. S. Smith in 1876. Sylvester, in response to a criticism of pure mathematics by T. H. Huxley, likened the discoveries of pure mathematicians to those of an explorer in the wild. In his presidential address to the LMS, Smith defended pure mathematics as "a necessary concomitant of a vigorous and expanding Empire" [p. 208]. While Heard critiques both of these defenses of pure mathematics and then deems them 
as ineffectual, he does not provide any contemporary evidence of the public's negative reaction to them.

Heard's final chapter presents what he believes was the crucial argument pure mathematicians found to legitimize their discipline to the Victorian public. He begins with Walter Pater's 1873 Studies in the History of the Renaissance, which reframed how one should appreciate art and beauty, and the ensuing Aesthetic "tendency" embraced by "a flamboyant group of artists and writers led by the painter James McNeill Whistler and, later, by the poet, essayist and playwright Oscar Wilde" [p. 215]. By 1883, George Salmon wrote in the journal Nature an appreciation of Arthur Cayley as "an artist, a maker and contemplator of the beautiful, and thereby allied him not with Scientists... but with poets and painters" [p. 220]. Heard claims that this reframing of the pure mathematician as a creator of beauty "would eventually reverse the relative degrees of esteem in which pure and applied mathematicians were held. Consequently, by the turn of the century pure mathematics in Britain had gained a permanent place alongside other disciplines that were deemed to be worthy of a lifetime's study" [p. 226]. As evidence of the public's opinion of pure mathematicians, Heard gives the examples of an 1883 poem from Punch, a popular satirical magazine, and Miss Cayley's Stories, a series published in the Strand Magazine in the late 1890s and subsequently published as a book. More evidence of the public's changing views on pure mathematics and mathematicians would have been a welcome addition to this chapter.

The Mathematical Tripos eventually abolished ranking its wranglers; Heard would do well to follow suit. Statements such as "no British pure mathematician could be mentioned in the same breath as the greatest of the Continentals" [p. 245] obscure more useful observations about how these mathematicians at the time saw themselves and their colleagues. ${ }^{1}$

Overall, Heard writes in a very engaging and interesting style. He has a knack of taking a "wide-angle-lens" view of the history of mathematics that would appeal to the general reader, and he makes connections that are interesting and unexpected. While this approach has many virtues, it artificially straightens some of the curves in the road on the journey through Victorian mathematics. Heard's aesthetic argument is compelling, but he seems to attribute the entirety of Britain's acceptance and appreciation of pure mathematicians to it. In order to meet that high bar, his argument needs more contemporary evidence, international context, and attention to the existing literature (for example, [3]).

\section{References}

[1] Sloan Evans Despeaux, The development of a publication community: Nineteenth-century mathematics in British scientific journals, Thesis (PhD)-University of Virginia, 2002. MR2703853

[2] Sloan Evans Despeaux, Mathematics Sent Across the Channel and the Atlantic: Nineteenth-Century British Mathematical Contributions to International Scientific Journals, Annals of Science 65 (2008), no. 1, 73-99. MR2417934

[3] Raymond Flood, Adrian Rice, and Robin Wilson, eds., Mathematics in Victorian Britain, Oxford University Press, 2011. MR2885274

[4] Joan Richards, Reviewed Work: Mathematics in Victorian Britain, Isis 104 (2013), no. 4, 853-855.

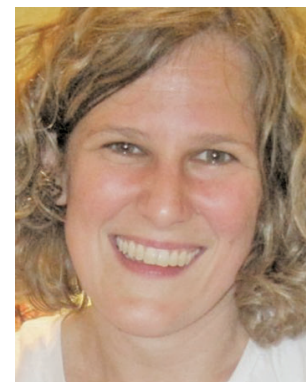

Sloan Evans

Despeaux

\section{Credits}

Book cover reproduced with permission of The Cambridge University Press through PLSclear.

Author photo is courtesy of Sloan Evans Despeaux.

\footnotetext{
${ }^{1}$ For a similar view on what can be lost when placing modern rankings on mathematics and mathematicians of the past, see [4].
} 